Revista Iberoamericana. Vol. LXIV, Núms. 182-183, Enero-Junio 1998; 97-106

\title{
LIMIARES CULTURAIS: AS COMPLEXAS RELAÇÕES DO SUL/SUR
}

\author{
POR \\ Tânia Franco Carvalhal \\ Universidade Federal do Rio Grande do Sul
}

Nadie ignora que el Sur empieza del otro lado de Rivadavia.

(J. L. Borges)

\section{A GEOGRAFIA DA PÁTRIA}

Como no conto de Borges, do qual foi extraída a epígrafe acima, o Sul (el Sur), nas literaturas argentina e brasileira, é realidade e metáfora. Realidade geo-política, que acaba por reproduzir no Novo Continente uma oposição Norte/Sul, originalmente européia, com a inflexão particular que ganha na segunda metade do século XIX quando ali o Sul, além de aludir a uma oposição entre riqueza e pobreza de regiões, ligase às noções de latinidade, catolicismo, decadência. No paradigma construído, esse Sul opõe-se ao Norte anglo-saxão, ao protestantismo, ao progresso.' Como metáfora, integra um vasto campo mítico no âmbito do qual também se situa a figura do gaúcho (el gaucho), ser marginalizado com sua montaria, a viver em estado de barbárie numa região de deserto (la llanura, o pampa).

O Sul é, nesse contexto, espaço de violência e de vazio, contrapondo-se ao Norte, ao outro lado, lugar da civilização e das cidades. Recupera-se, aqui, sem dúvida a oposição firmada por D. F. Sarmiento entre "civilização e barbárie".

Mas ainda no conto de Borges, o Sul não é uma simples convenção. No recorte da cidade, atravessar "Rivadavia", avenida que cinde Buenos Aires em duas metades, significa entrar en un mundo más antiguo y más firme. Como lugar onde tudo é vasto e despovoado, constituído de estancias, o Sul é o depositário do passado e da memória do país em seus primórdios e em seus elementos mais particulares.

É curioso observar que a parte Sul da cidade, preservava, para Borges, o encanto do passado. Assim o relata Emir Rodríguez Monegal em Borgès ao recordar os passeios com o escritor pelas ruas de Buenos Aires nos anos 40:

\footnotetext{
${ }^{1}$ Veja-se sobre a questão, Rivas (459-467).
} 
Mal chegávamos nos bairros sul de Buenos Aires, Borges tornava-se outro. Esses bairros dão a impressão de que o tempo ali está suspenso (ou davam esta impressão nos anos 1946, 1947, 1948 que estou a evocar) como cenário de um filme de Borges (Rodríguez Monegal 119).

Assim, eles entravam em cafés, passavam por pátios ou praças, ouviam tangos antigos que os remetiam à época de Juan Manuel de Rosas e de seus avós, reencontrando uma espécie de Buenos Aires mítica. Portanto, o Sul está ligado indissoluvelmente a um tempo anterior, primordial que o reveste de uma aura nostálgica.

Não é outro o significado com que é recriado, por exemplo, nos contos do escritor brasileiro João Simões Lopes Neto, reunidos em Contos Gauchescos (1912) e Lendas do Sul (1913) onde o cenário é a campanha sul-rio-grandense e tudo se passa nos primeiros tempos. Por isso, escreve no conto "No Manantial": "Estes campos eram meio sem dono, era uma pampa aberta, sem estrada nem divisa; apenas os trilhos do gado cruzando-se entre aguadas e querências" (Simões Lopes Neto 64). Ou em outro desses textos, intitulado "O Negrinho do Pastoreiro": "Naquele tempo os campos ainda eram abertos, não havia entre eles nem divisas nem cercas; somente nas volteadas se apanhava a gadaria xucra e os veados e as avestruzes corriam sem empecilhos ..." (Simões Lopes Neto 179).

Se o personagem borgeano, ao atravessar a cidade e dela afastar-se, adentra $a$ geografia da pátria, o de Simões Lopes Neto cruza o Estado em caprichoso ziguezague. Essas errâncias são indicativas de uma busca, certamente a de um traçado que se quer preservar, de uma ligação entre passado e presente, de um desenho de pátria associado a valores antes vigentes, da sensação de liberdade que a amplidão evoca. Observe-se, nesse sentido, como essa conotação comparece inclusive na representação que ganha o Sul nos domínios do popular. É o que se constata na canção "Vuelvo al Sur", de Astor Piazzolla e Fernando Solanas (Argentina, 1988), na qual "volver al Sur" significa reencontrar os valores mais simples e autênticos e ainda reconhecer-se com uma identidade própria:

Soy del sur

Como los aires del bandoneón

A procura do Sul, na canção, coincide igualmente com a busca de qualidades positivas existentes no passado:

Busco el Sur

El tiempo aberto y su después

Quiero el Sur

Su buena gente, su dignidad 
Em todos esses textos, mesmo sendo o Sul um espaço aberto, de horizonte largo, seu alcance está relacionado a uma travessia: em Borges, de uma avenida, nos demais, de um país. Assim, chegar ao Sul é cruzar uma fronteira: seja a que divide a cidade e, nos textos do autor sul-rio-grandense, corresponde a toda uma região que é divisa do Brasil com os países do Prata. Contudo, trata-se sempre de uma fronteira frágil, facilmente transposta. O vizinho é sempre o que está do outro lado ou "o da banda de lá", numa clara alusão à Banda Oriental. Desse modo, como fronteira transitável, é lugar privilegiado de contrabando entre regiões contíguas que estabelecem entre si um comércio não legalizado mas que funciona como se o fosse, com base no entendimento mútuo de trânsito necessário e no vaivém que se estabelece, desde sempre, entre os dois lados. Nesta terra do Rio Grande sempre se contrabandeou, desde em antes da tomada das Missões, lê-se em Simões Lopes Neto (89), numa constatação sem malícia de um hábito já arraigado.

Temos, portanto, ao lado de uma concepção do Sul como o interior da pátria, sua parte menos modificada pela civilização e mais próxima às suas origens, também o Sul como uma vasta região fronteiriça na qual se dá o intercâmbio econômico, lingüístico e cultural que facilita os contatos e faz ressaltar, no conjunto, semelhanças e diferenças. É, pois, no contexto que estamos examinando, uma sub-região com dois lados (ou duas faces do mesmo lado) — Sul e Sur - sendo simultaneamente realidade geográfica, que favorece a convivência, o intercâmbio e as trocas e metáfora literária, que preserva o passado e alimenta a imaginação.

\section{O CONE Sul/ El Cono Sur}

Os textos literários nos auxiliam a sintetizar uma situação que é historicamente conhecida embora hoje assuma outra consistência pela construção de um bloco político e economicamente solidário designado Mercosul. A criação desse "mercado comum", constituído com a finalidade de fortalecer as economias dessa sub-região, pelo estabelecimento de um sistema interno de consumo que assegure a produção, nos encaminha à reflexão sobre as relações culturais que, na seqüência das existentes, começam a se delinear como necessárias e mesmo desejáveis.

A reunião em um mesmo conjunto de Brasil, Uruguai, Argentina, Paraguai e, mais recentemente, o Chile nos propõe certamente indagações sobre as culturas postas lado a lado no tipismo de suas diferenças intra-regionais e no tipismo de suas semelhanças dentro do conjunto sul-americano mais amplo. Além disso, indaga-se de que natureza são as fronteiras que determinam o recorte do conjunto ou, ainda, que função podem ter a literatura e as demais formas de expressão cultural numa construção cujos fundamentos são substancialmente de ordem política e econômica.

Como observação preliminar, sabe-se que os processos internacionais de globalização econômica e cultural estão nas raízes da criação desse bloco não tendo ele sido gerado, por exemplo, por reflexões que propunham uma nova cartografia dos 
países vizinhos, como a de Ángel Rama em Transculturación Narrativa en América Latina. Com base em dados fundamentalmente culturais sobre a América Latina, Rama alertava que, sob uma unidade exterior e aparente, "real en cuanto proyecto, real en cuanto a bases de sustentación, se despliega una interior diversidad que es la definición más precisa del continente". Nesse conjunto, creditava a diversidade à existência de regiões culturais claramente delineadas e que fugiriam ao desenho da cartografia oficial, estabelecida sob argumentos políticos e mesmo geográficos. Por isso dirá:

Estas regiones pueden encabalgar asimismo diversos países contíguos o recortar dentro de ellos areas con rasgos comunes, estabeleciendo así un mapa latinoamericano cuyas fronteras no se ajustan a las de los países independentientes. Este segundo mapa latinoamericano es más verdadero que el oficial cuyas fronteras fueron, en el mejor de los casos determinadas por las viejas divisiones administrativas de la Colonia y, en una cantidad no menor, por los azares de la vida política, nacional o internacional (Rama 58).

Segundo Rama, ao considerarmos a perspectiva de regiões, neste "segundo mapa el estado Rio Grande do Sul, brasileño, muestra vínculos mayores con el Uruguay o la región pampeana argentina que con Mato Grosso o el nordeste de su propio país; la zona occidental andina de Venezuela se emparenta con la similar colombiana y mucho más que con la región central antillana" (Rama 58).

Restabelecer, portanto, a cartografia latino-americana com base em relações de proximidade e de diferenças, corresponde a alterar o ângulo contrastivo que, de hábito, volta-se para o exterior do continente com vistas à diferenciação com as culturas externas para traçar a suposta "unidade". A nova perspectiva contempla "uma diferenciação interna", como diz o crítico, "mediante un correlativo sistema de oposiciones que se funda principalmente en los criterios de la antropología cultural, aunque cuenta con el refuerzo de la historia y de la más reciente economía" (Rama 60).

Assim, embora o móvel da construção do conjunto não tenha sido as relações culturais que existem entre os países da região, reflexões como a do crítico uruguaio alertam para que se reponha essa dimensão na análise do conjunto.

A utilidade e a importância das considerações de natureza cultural ressaltam na medida em que se leva em conta os riscos de "padronização", de "homogeneização" ou de "seriação" que processos dessa natureza trazem em si mesmos. De um lado, as equivalências e os paralelismos que se estabelecem, com vistas a facilitar a circulação de mercadorias, podem conduzir a uma certa padronização entre elas; de outro, a natureza contingente e circunstancial da criação do conjunto pode neutralizar o que, ao longo dos tempos, tem sido marca de um percurso de afirmação dos países do continente: busca de identidade e de legitimação de suas peculiaridades.

Não obstante, se os desafios de uniformização existem, gerados pela união que embasa a própria construção do conjunto, não se pode desprezar os dados que temos sobre as possibilidades de coexistência de diversidades em uma totalidade circunstan- 
cialmente construída. Sabe-se, hoje, que a simples oposição antagônica de elementos distintos não subsiste para evitar a dissolução das partes no todo mas que é possível buscar a complementaridade de funções entre o que é diferente, não em sentido utópico ou artificial, mas no entendimento de que cada particularidade pode encontrar o seu lugar em uma totalidade, sem nela desaparecer. Há, é certo, um remodelamento das relações antes determinantemente opositivas, pois os interesses comuns, quando contingentes e contextualizados, acabam por regular as relações das diferenças entre si. $^{2}$

Estaríamos, assim, perto da concepção que Carlos Fuentes designou em Valiente mundo nuevo, como preservação da diversidade na unidade, pois, no campo das analogias, que asseguram e mesmo justificam a organização do conjunto, o que nele interessa ainda acentuar são as suas diferenças.

\section{PróXIMOS MAS DIFERENTES}

Lo original de cualquier cultura es su misma originalidad, la imposibilidad de reducirla a otra, por más fundamentos comunes que compartan.

Ángel Rama

Com uma história paralela, malgrado as peculiaridades que caracterizaram os respectivos processos de colonização portuguesa e hispânica, os países integrantes do Cone Sul (geograficamente, Argentina, Uruguai e Chile e, no Mercosul acrescidos de Brasil e Paraguai) manifestam a existência de traços que os aparentam embora não sejam suficientes para os igualar.

É sabido que o povoamento dessas regiões, além de tardio, foi majoritariamente de europeus que nelas encontraram condições climáticas favoráveis ao desenvolvimento de culturas agrícolas similares às de seus países de origem. Distinguindo-se de algumas regiões da América Latina (notadamente México e Peru) pela pouca riqueza de minérios e por uma povoação indígena menos sedentária e menos desenvolvida culturalmente, os países dessa sub-região têm, entre outros elementos, como a vocação à pecuária e à agricultura, certas paisagens comuns.

Essas paisagens são marcadas pela aparência desértica, pela amplidão: o pampa (do Sul do Brasil, da Argentina e do Uruguai), a Patagônia, o deserto de Atacama. Os traços que as associam - grandiosidade da natureza contraposta à pequenez do homem, aridez, vazio e silêncio- se reproduzem por vezes em outras regiões dos respectivos países, com variantes, como no sertão brasileiro, na selva amazônica ou na região andina.

A paisagem é, nesse caso, uma referência simbólica que aliada à idéia de grandes dimensões alude à noção de isolamento e, por extensão, de desterro cultural. ${ }^{3}$

\footnotetext{
${ }^{2}$ Veja-se Laclau, Emancipación y diferencia.

${ }^{3}$ Veja-se Carvalhal $(9-16)$.
} 
Vista assim, permite apontar para uma série de elementos comuns, surgidos de uma história compartilhada e da situação de vizinhança que estabelece zonas de contato através das quais migram fatores culturais de um lado para outro em processo de contágio e assimilação. Contudo, mesmo que se possa tecer um amplo quadro de analogias, com base em dados geográficos, em hábitos e costumes intercambiados, em características étnicas, em similar formação cultural pelo recurso a idênticas fontes européias, que originaram procedimentos literários semelhantes nos contexto em estudo, ou o exercício comum de um certo imaginário popular afim, sempre haverá a impossibilidade de redução de uma cultura a outra, pois o que ocorre é uma transculturação, no sentido mais criativo do termo, tal como o delineou o cubano Fernando Ortiz (Rama 33 et seq.), acrescido de "seletividade e inventividade", como o completou o próprio Rama. A seletividade nas incorporações é recurso que determina todo o processo de intercâmbio nas relações culturais, caracterizando as culturas em contato como atuantes e dinâmicas, capazes não só de selecionar mas de incorporar criativamente o que lhes interessa.

Por outro lado, as diferenças de condições de produção cultural nos países que constituem o conjunto é que irão explicar o surgimento de um escritor universal como Machado de Assis, no Brasil acanhado do século XIX, e de um cosmopolita como Borges, na Argentina nacionalista do século seguinte. ${ }^{4}$ Do mesmo modo, através das análises das condições de difusão e de recepção, da constituição de centros culturais em cada país, da circulação externa e interna das respectivas literaturas, há de se tentar esclarecer por que Borges é um escritor universalmente conhecido enquanto Machado de Assis é pouco difundido na Europa, nos Estados Unidos e mesmo na América Latina. Esses dados servirão certamente de indicadores para que se entendam as relações culturais entre os países que hoje se encontram associados numa totalidade construída.

LIMIARES CULTURAIS: TRAVESSIA LITERÁRIA

Pero nadie puede ser como el otro, dejando de ser lo que él es (A. Zum Felde).

A mulher de André Vicente gostava de me dar confiança porque no tenía hijos.

(Sergio Faraco)

Se os processos de globalização e de mundialização cultural se reproduzem na constituição de blocos de integração regional, se os limiares de toda a natureza (teóricos, teórico-críticos, institucionais, culturais, discursivos, literários) se diluem, as fronteiras, antes demarcadas, adquirem agora uma identidade ambígua: perdem o

${ }^{4}$ Uma perspectiva importante dessa questão foi tratada por Antonio Canido em Formação da literatura brasileira, vol. II, cap. 3, 117-8, e retomada por Davi Arrigucci Jr. em "Da Fama e da infâmia", 198. 
estatuto de serem o limite da diferença (de moeda, de nacionalidades, de condutas, de costumes e normas) em favor da livre circulação e do trânsito (comercial, de força de trabalho, de hábitos culturais). Nesse contexto, como viver a experiência do outro sem perder a si mesmo?

Esta indagação central nas relações que regem as trocas e os intercâmbios culturais do Cone Sul pode ser respondida pela frase do crítico uruguaio, Alberto Zum Felde, antes reproduzida, na medida em que ressalta que para viver a experiência do outro é necessário preservar aquilo que a cada um é próprio. Isso significa dizer que os limiares, mesmo quando aparentemente neutralizados, sempre existirão, pois o contato permanente, que facilita o conhecimento, não elimina as peculiaridades de cada cultura. Ao contrário, em todo processo de transculturação a abertura para culturas alheias não provoca necessariamente a perda do que a cada um pertence mas o aproveitamento seletivo conduz a uma apropriação que pode ser altamente criativa. Isso porque a assimilação sempre se efetuará com base no existente, que dimensiona e orienta o processo de apropriação. São esses procedimentos interculturais que irão caracterizar as zonas fronteiriças como espaços híbridos, onde se mesclam línguas e hábitos culturais, favorecendo a integração.

No conjunto do Mercosul, que reúne países de fala hispânica e o Brasil, portanto, falar o espanhol não significa deixar de expressar-se em português (e vice-versa) mas é certo que a aprendizagem da língua do outro facilita o acesso e o melhor entendimento da cultura vizinha. Por isso o ensino das respectivas línguas se tem fortalecido nos diversos países, já que a boa comunicação lingüística facilita os contatos e promove o congraçamento.

Com efeito, a mescla lingüística é uma marca das zonas fronteiriças onde vocábulos, expressões e mesmo estruturas frasais migram além fronteiras ganhando difusão "no outro lado".

A literatura, portanto, registra o processo de hibridização ao recriar situações concretas da realidade de fronteira. É o que ocorre exemplarmente no conto "Travessia", incluído no livro Noite de matar um homem (1986), do escritor sul rio-grandense Sergio Faraco. Ao narrar a passagem de um contrabando entre Argentina e Brasil numa travessia de rio, Faraco utiliza a perspectiva de um narrador-menino. É sob a sua ótica que a situação e os acontecimentos dela decorrentes são expostos ao leitor. Assim, ao representar uma personagem feminina no conto, "dona Zaira" (a mulher de André Vicente, o dono do rancho onde os contrabandistas aguardavam a hora propícia para a travessia do rio), o jovem narrador diz que ela sempre tinha para com ele alguma atenção especial e isso porque "no tenía hijos". Na frase integralmente transcrita em epígrafe pode-se verificar a alternância natural, sem transição demarcada, das duas línguas em contato na fronteira do Sul do país - português e espanhol- reproduzindo uma experiência real de mescla lingüística. Tal recurso serve também para configurar, de imediato, a origem hispânica da personagem e dizer-nos que ela, embora vivesse "do lado de cá", pertencia originalmente "ao lado de lá". A coexistência das duas línguas na mesma frase é, portanto, estratégia narrativa para recriar diante do leitor uma figura 
e caracterizá-la. Se indica sua origem pela reprodução de um fragmento de fala, alude também a uma união comum em zona de fronteira: a dos pares formados por parceiros de dois lados. Desse modo, está a apontar, ainda, para a mescla das origens, aproximadas por cumplicidades e parcerias.

De certa maneira, a narrativa de Sergio Faraco concretiza o que o crítico uruguaio Zum Felde observou, pois ao fazer o uso simultâneo e complementar das duas línguas o narrador comprova que apropriar-se da fala do outro, significa torná-lo presente, e que esta língua híbrida expressa o acréscimo e não a redução ou perda de seu próprio instrumento de expressão. Quer dizer, o recurso literário-discursivo tem no conto uma dupla função: logra a síntese na representação da personagem que nos é dada de um só golpe e recria, linguisticamente, a realidade de fronteira onde os intercâmbios culturais são freqüentes e os limiares mais neutralizados.

É curioso observar que na tradução do conto, incluído em Noche de matar un hombre (1988), o recurso se dilui, pois a frase é dada integralmente em espanhol: "A la mujer de Andrés Vicente le gustaba darme confianza porque no tenía hijos" (33). Percebe-se, então, que para manter o efeito logrado na língua original haveria de deslocar a personagem de lado, isto é, colocá-la "na outra banda", falando português. Esse pequeno artifício possibilitaria preservar o recurso, assegurando no processo de tradução (trans)criativa os efeitos de representação que o texto original lograva.

Tal questão nos diz da importância do exercício interpretativo precedendo a tradução para que ela recrie, na língua de chegada, o texto primeiro em seus procedimentos essenciais.

Os contos de Sergio Faraco, majoritariamente situados no Sul do Brasil, recriam valores eternos (como coragem e lealdade) que se expressam através de personagens simples e anônimos. No mesmo "Travessia", ressalta a dignidade com que o tio contrabandista se desfaz do contrabando para fugir à guarda da fronteira. Em muitos textos, o silêncio de certas personagens, em geral lacônicas em suas manifestações, diz mais do que falas longas e tagarelas. Depois de Simões Lopes Neto é certamente Sergio Faraco quem melhor traduz no conto as peculiaridades da região Sul do Brasil, inserindo na ficção brasileira, sem particularidades dialetais, a expressão de um modo de ser e de enfrentar as situações que identificam e distinguem o Sul/Sur. Isso porque, em sua obra pode-se analisar de várias maneiras os processos das relações interculturais com os países do Prata, em particular nas vizinhanças com o Uruguai e a Argentina, seja na produção contística ou nas inúmeras traduções que realiza. ${ }^{5}$ Em sua obra percebese com clareza que a literatura trabalha nos limites, nas margens (nos limites dos gêneros, nas margens dos textos e das culturas, no espaço intervalar onde se concretiza o imaginário das zonas de contato que facilitam o processo permanente de interação de elementos vários).

\footnotetext{
${ }^{5}$ Entre as obras de Sergio Faraco é essencial ler, com essa perspectiva, Hombre, Manilha de espadas, Contos completos e Mario Arregui \& Sergio Faraco: correspondência.
} 
Percebe-se, então, que os procedimentos literários empregados por autores que fixam a vida nas fronteiras são de exame indispensável para o entendimento das conformações culturais supra-nacionais, de demarcações diluídas pelo hibridismo. Fica claro que a literatura verdadeiramente rompe barreiras, cruza fronteiras nacionais e discursivas- e concretiza as relações interculturais. ${ }^{6}$

Esse atuar "entre", na exploração de limites, esse investigar a ultrapassagem e a diluição de fronteiras na constituição de conjuntos supra-nacionais é central aos estudos de literatura comparada, que se ocupam preferencialmente com a análise constrastiva dos procedimentos caracterizadores da construção das literaturas nacionais bem como contribuem para o conhecimento dos modos como elas interagem na constituição de conjuntos regionais e como se integram à literatura universal. Duplo movimento que atenta para a apropriação criativa do alheio, a afirmação do próprio e sua inserção no geral.

Assim entendido, o comparatismo contrastivo, que tem sido essencial para o estudo das literaturas latino-americanas, contribui decisivamente para a análise das complexas relações dos limiares culturais e para o entendimento das questões relativas ao Sul/Sur.

\section{OBRAS CITADAS}

Arrigucci Jr., Davi. "Da fama e da infâmia (Borges no contexto literário latinoamericano". Enigma e comentário. São Paulo: Cia. das Letras, 1987.

Candido, Antonio. Formação da literatura brasileira. 2 vols. São Paulo: Martins, 1959.

Carvalhal, Tania Franco. "O lugar da literatura comparada na América Latina". Boletim Bibliográfico. Biblioteca Mário de Andrade. São Paulo: Secretaria Municipal de Cultura, 1986. 9-16.

"Comunidades interliterárias e relações entre literaturas de fronteira". Raúl Antelo, Identidade e representação. Florianópolis: Ed. da UFSC, 1994. 93-102. "Fronteiras em Literatura". Práticas de integração nas fronteiras - temas para o Mercosul. Porto Alegre: Ed. da UFRGS, 1995. 160-164.

Faraco, Sergio. Noite de matar um homem. Porto Alegre: Mercado Aberto, 1986. Noche de matar un hombre. Montevideo: Editorial Monte Sexto, 1988.

Hombre. Rio de Janeiro: Civilização Brasileira, 1978.

Manilha de espadas. Rio de Janeiro: Philobiblion Livros de Arte, 1984. Contos completos. Porto Alegre: L \& PM, 1995.

Mario Arregui \& Sergio Faraco: correspondência. Montevideo: Ed. Monte Sexto, 1990.

\footnotetext{
${ }^{6}$ Veja-se Carvalhal, "Comunidades interliterárias e relações entre literaturas de fronteira" e "Fronteiras em Literatura".
} 
Fuentes, Carlos. Valiente mundo nuevo - Épica, utopía y mito en la novela hispanoamericana. México: Fondo de Cultura Económica, 1990.

Laclau, Ernesto. Emancipación y diferencia. Buenos Aires: Ariel, 1996.

Rama, Ángel. Transculturación narrativa en América Latina. México: Siglo XXI Ed., 1982.

Rodríguez Monegal, Emir. Borgès. Paris: Seuil, 1988.

Rivas, Pierre. "Un Sud politique? Latinité sociale et fédéralisme méditerranéen entre 1880 et 1915". Colloque de Littérature Générale et Comparée (Montpellier III, 1980): 459-467.

Sarmiento, Domingo Faustino. Facundo. 1845. Buenos Aires: Editorial Losada, 1963.

Simões Lopes Neto, João. Contos gauchescos e Lendas do sul. 1912, 1913. Porto Alegre: Editora Globo, INL/MEC, 1973. 